\title{
Opening up conceptions of rights
}

$\mathrm{T}$ HIS BOOK'S ARGUMENT takes as its point of departure the question of how to promote human rights observance in international life. The whole complex business of international human rights promotion is not approached here as a particularly 'innocent' enterprise. On the contrary, the various philosophical and ethical claims of rights promotion, its actual as well as proclaimed political functions, outcomes and implications - what could be summed up as the 'virtue' of the enterprise in entirety or in part - can be readily questioned from many directions. Nevertheless, for this work the aim of questioning human rights promotion is ultimately practical and the standpoint of the question 'committed'. This commitment, however, is not to advocacy of the idea of human rights per se, when that idea refers to either a universal transcendental attribute thought to be inherent in individuals or to a sociolegal attribute considered essential to the proper functioning of states. The commitment is rather to human rights, and its crucial category of abuse, as an available language and tool for articulating suffering in a political voice, for asserting the value and the vulnerability of people, and for grappling with the on-going question of how we value each other in the complex circumstances of our different and interwoven lives.

For reasons that will become clearer as the argument progresses, the understanding of human rights emphasised and explored in this work is an open-ended one. Rather than aiming for definitional clarity - often a valuable goal - the concern here is to open out discussion by stepping aside from some of the categories and models that dominate much promotion of human rights, particularly in the international arena. Ways of talking about human rights and systems for defining and implementing them have their own complex histories and particularity. The argument here, however, proceeds from the understanding, or the presumption, that questions of human rights are also part of the much broader context of people's repeated efforts to work against the systemic infliction of suffering in political life and to 
create conditions of life that do not turn upon the generation of such suffering.

'Suffering' is used here (though the more common terms 'abuse', 'injury' and 'harm' are also used) as an element of this open-endedness. John Donnelly (1999), a leading theorist of human rights, emphasises the importance of keeping definitions of human rights focused and of recognising that not all suffering is a matter of rights. While agreeing that not all suffering is a matter of rights, or is political, here I want to take a different approach - to question the scope of the term 'human', to draw attention to the shifting range of what is counted as 'political', to offer a reminder that there is suffering that we have not seen and do not see and of the sometimes acutely political nature of this 'not-seeing'. The 'overlooking' of the suffering of others, and the denial that such suffering could claim any part in the dynamics of our collective political orders, has a long, highly respectable and continuing record. All suffering is not political but the line between what is and is not, is not settled and demands attention.

'Suffering' is also an evocative term. Whereas the language of rights and abuse, of claim and obligation, can appear to offer a proper balance of settled equivalences and hoped-for justice, 'suffering' can work as a reminder that the reality of pain, loss and trauma, even within indisputably political exchanges, can pose dilemmas not easily contained within our moral languages (Connolly, 1993).

In the first instance, however, human rights are approached here as particular kinds of conceptual and practical tools, as bundles of social, institutional and legal practices and complex ways of talking and doing for practical, if often general and recurrent, circumstances and purposes. That is, the task of understanding human rights is not presumed to be one of capturing an entity intrinsic to the person, where rights are sometimes cast as markers of transcendental individualism, or of grasping a specific body of rules or capacities intrinsic to all possible forms of civilised political order. As tools that shape us as we shape them, specific practices and models of human rights have their own histories and modes of operation. They are dynamic and evolving, as traditions and languages are. Moreover, as the following chapters argue, particular models of human rights can work differently in different contexts and can not be presumed to be invariably beneficial or emancipatory.

Though not a fixed entity or a categorical imperative, the subject matter of human rights is not therefore understood as lightly malleable. Physical pain, which is frequently the mechanism or imprint of abuse and the means by which dominance is directly or indirectly claimed and enforced, has a powerful, even overpowering, reality. As Elaine Scarry (1985) makes clear, for the sufferer pain is a form of certainty intrinsic to being a body - which for others is transformable into a political weapon. For those who use it as a weapon pain is an assertion of domination which, because never able to be genuinely certain 
or secured, must be asserted again and again. As an instrument of political organisation, suffering is an obdurate reality, however unwieldy and evasive its boundaries, forms and significance can be.

To draw attention to human rights practices as tools is also not to cast them as purely mechanistic, existing only in their specific institutional forms within the state or in inter-state regimes, in laws, regulations or established norms. Despite the crucial significance of these institutional forms, it is argued here that it is part of the practical value of the idea of human rights that it is not quite reducible to them. If the language and practices of human rights are tools, they are fluid, with often difficult and unsettling purposes and potentials. They can work to register and respond to the intolerable, ${ }^{1}$ to engage with the deep-rooted patterns of injury that we inflict on each other, and so are as capable of confounding norms of proper action as they are of confirming them. Whether or not notions of human rights are the 'best' tools for such tasks is perhaps beside the point - they are part of what is to hand.

The forms of 'rights talk' most prevalent in human rights promotion and debate, particularly in the domains of interstate politics, take a somewhat different approach. There are indeed many ways of understanding and talking about human rights. In terms of conceptual framework or of particular cases and causes, human rights are routinely a matter for debate by philosophers, legal theorists and practitioners, political theorists, social and political activists, religious figures, state and foreign-policy makers, and so on. They are an arena of both passionate contention and relentless scepticism and, for those of us in liberal democratic traditions and social institutions, they touch on some of our most potent political icons and foundational referencepoints - points so foundational that they are elusive and naturalised almost to invisibility. But patterning this quite diverse field is a repeated motif or model or story (albeit with many variations) of the genesis and nature of rights. This is a story of rights that draws on the idea of the social contract, particularly in its Lockean form. It is an account that dominates much of the effort to articulate abuse and to stop or restrain its repetition, particularly in the international arena.

In the following chapters, the argument considers critically this dominant 'story' of rights, touching briefly on some of the other approaches to human rights, or the sub-themes, with which the Lockean account is in practice interwoven. My purpose here, firstly and most importantly, is to step aside from the certainty with which the central organising categories of the dominant accounts of rights, particularly those of the human individual and of the community, are held. This is not because the ways of talking and acting made available by these categories are bankrupt or particularly poor - they have in any event deeply shaped the forms of our political communities. It is rather because these categories are limited while too often claiming to be limitless; they can be 
destructive while claiming to be liberatory; and they certainly exhaust neither the questions with which abuse confronts us nor the complexity of human life. And, secondly, the purpose of reflecting on the Lockean story is to explore at least some of the effects that our dominant constructions of human rights have had on efforts to work with cases of abuse or suffering as an instrument of political organisation. Questioning categories of the human, the individual and the community is an underlying if sometimes distant theme of this work, - just as it is a challenge thrown out by confrontation with suffering and abuse. Challenging the categories in which so many claims to moral certitude are grounded need not destabilise the basis for working with human rights. A preparedness in the context of practical engagement with human rights issues to question vigorously these categories can enable debate to shake loose from some of the sterile dichotomies (the 'individuality' of the West in contest with the 'communitarianism' of the East, for example) that suffocate exchange on questions of how we live our collective lives. And it may encourage the growth of working rights practices that are more responsive to the forms of suffering, exclusion and exploitation that we both inflict and endure.

As a set of conceptual and practical tools, notions of human rights are a very mixed bag. It is part of many classic accounts of rights (John Donnelly's work is notable here) to say that the idea is essentially a Western and liberal construction; that however universally applicable or otherwise the idea of rights may be argued to be, it was forged and reforged in the struggles and debates of sixteenth-eighteenth-century Europe and the United States - struggles from which the modern liberal state, the modern market economy, the modern individual and the ascendancy of what are seen as 'secular' and 'civic' rather than 'sacred' virtues took shape. Indeed, notions of human rights were one, deeply contentious, thread in the long effort to piece together a political modus vivendi well apart from the bloody divisions surrounding the relationship between sovereignty and the various versions of ultimate truth that marked the Wars of Religion. As R. B. J. Walker (1993) has suggested, through the slow elaboration of the sovereign state as the central organising principle, this modus vivendi enabled the simultaneous assertion of the state as both a universal, selfconsciously secularised form of collective order and progress and a principle of radical differentiation.

Certainly the early modern debates and their elaborations and revisions in the following centuries seam deeply the ways we construct human rights and the sort of tool we make of them. In very general terms, these debates tend to cast concrete struggles for greater freedom from the violent or degrading exercise of power in terms of an abstract tension between conceptions of universality and of differentiation. (The 'Asian Way' debate is one example of this circular dichotomy.) Or categories for recognising and responding to the systemic infliction of suffering are conceptualised in terms of the relationship 
between the individual as a rational calculator and the state as an ideally neutral and homogenous political space. Or people's diverse desires to live according to their own collective ways, as James Tully (1995) has pointed out, are packed into the confined vocabulary of the independent nation state, as numerous entrenched and bloody separatist conflicts demonstrate.

The past few centuries of struggle, debate and administrative efforts around questions of human rights represent a protean and in many ways rich inheritance. The traditions and language of rights that have slowly taken shape in these on-going debates are called upon both to communicate a potency of aspiration that is in no sense peculiarly Western and also, on a more immediate level, to sustain a significant network of local, national and international practice that is not always reducible to the pressure of Western institutions or "paradigms from the Centre'. However, as the later chapters of the book argue, the instruments that at least the dominant traditions of rights bequeath, and in particular the categories of 'community' and of 'person' in which understanding of human rights is routinely embedded, have also carried their own forms of damage, their own significant myopias and exclusions. The language of human rights has at some junctures given expression to and been shaped by otherwise silenced voices - of indigenous and colonised peoples, women, alienated minority peoples, urban and rural workers and the propertyless poor; at some junctures it has acted to deepen the deafness which has systematically excluded the voices of those constituted as inferior or as outcasts.

Approaching human rights as tools with significant but ambivalent potential places them as part of a broader conversation, across as well as within cultures and communities, on how to live well together. The significance of this is threefold. First, if we are considering whether and how we might work with a particular area of abuse, it helps to clarify which matters we are trying to pursue and which problems we are trying to make progress with. There are often many agendas at work in human rights promotion, certainly in the international arena. It is important to recognise which of any given set of circumstances is being accorded priority. Second, this more general approach to human rights allows discussion to step aside from the assertion of or the search for certainty that drives much work on human rights. And, third, a reduced preoccupation with certainty can encourage greater openness to the idea, and the task, of listening. For in the effort to shift those social and political practices in which systemic injury is often embedded it can be more valuable to be able to listen than to imagine we always have the answer. Such an approach enables the work of grappling with the concrete reality of abuse and suffering to step back from the assertions of ideological rectitude which often characterise rights talk. This is the core of the 'commitment' of this work and its ultimately practical standpoint.

Despite considerable differences of perspective, much of the theoretical 
work on human rights is an endeavour to anchor them; to define for them not only particular evolving shapes in particular political traditions but an essential role in a model of the good state, in legal reasoning, in logic, in an established realm of moral or human nature. Rights are often seen as close to the heart of the good life, particularly in liberal democratic perspectives, and yet our understanding of them is troubled by the anxiety 'that we do not as yet have a firm rational basis for pursuing rights and attempting to protect and uphold the rights claims of ourselves and others' (Bernstein, 1993: 19). Thus much theoretical elaboration of human rights is motivated by a search for certainty the endeavour to shape our understanding of rights according to a rigorous logical imperative from which a systematic analysis of their nature and scope can be extracted, defended and promoted. Understanding the truth about human rights - or about some of the ways in which we can live well together becomes an endeavour to secure a fixed propositional representation of the nature of things or to define permanently the conditions under which interchange can take place. Armed with a possessable truth, the hope goes, we are in a better position not only to expose without prejudice the hypocrisy and brutality of exploitative or violent practices but to insist on the enlightenment of less perceptive others, and, perhaps most importantly, to protect ourselves against the problems posed by our own collective histories of exploitative or violent choices.

People claiming universality for human rights can mean different things most simply and perhaps frequently that no one should be subjected to the kind of violence to which many people are relentlessly subjected. But in the more sustained elaborations of human rights the character of the universality that is claimed is commonly defined by the push for epistemic certainty (as the demand for certainty presupposes a certain construction of universality) - by the notion, criticised most notably by Wittgenstein, that epistemological grounding is the only reasonable basis for certainty and that with it one is armed with a truth that will fit any tangle of circumstance. Moreover, in this context, to assert the universality of human rights is generally to claim the (eventual) universal applicability of a particular model of the individual situated in the rational, secular space of the Westphalian state ${ }^{2}$ - of progress towards a particular, if broadly conceived, model of social order. That is, the character of the universality and the certainty sought by many approaches to human rights is one embedded in the historical emergence of the modern state.

And yet the effort of recognising and responding to abuse and the social practices in which it is embedded can raise profoundly difficult questions - questions that are liable to shake certainties as much as secure them. The massacres of the twentieth century, for example, of which for Westerners the Holocaust remains emblematic, raise questions that have no clear answers. The recognition of suffering can throw deeply embedded assumptions about the workings 
of political and social life into critical doubt; it can demand of us that we see our collective or individual selves differently - perhaps as inherently vulnerable, or as potentially complicit in abuse, or both. Hence the resistance of many immigrant states, for example, to acknowledging the persistent violence towards and suffocation of indigenous peoples and cultures which deeply mark, and perhaps made possible, their own history - their own immigrant stories of the struggle and survival of the human spirit and ideals of fairness and opportunity for all. Hence, too, the 'invisibility' of much systemically inflicted injury and the belief, common in many societies, that abuse, as opposed to the 'natural justice' by which the victims inevitably bring their fate upon themselves, is something that only happens somewhere else. Or the confusion which confrontation with sudden overt abuse can call forth - as in the case of the Tiananmen Square killings in 1989, which in some quarters at least elicited a momentary uneasiness that the working of the market may not lead naturally to political propriety. Questions of rights can interrogate the validity of our own collective and individual responses and intuitions across boundaries of culture, context and place.

Apart from the most general of injunctions and orientations and from the accumulated if often ambivalent lessons of our various histories, there are no clear answers to these questions. Indeed, the demand for a general, always intelligible, answer to such questions, for an overarching structure of philosophy or political theory which can guarantee that we will get it all 'right' seems a more than dubious enterprise. A propensity to generate unsettling questions may be central to the potency of ideas of human rights. It may be that such questions neither can nor need be fully resolved on a conceptual level, or that they will not be answered 'once and for all'. We resolve these questions well or badly, and again and again, in our intermittent practical efforts to live well together.

Indeed, one way of understanding the idea of human rights, at its most basic, is as a particular kind of question - the question or the web of questions with which the realisation of serious and systematic harm confronts us. At this most general level, human rights turn on the recognition of the suffering of another or of oneself, and they throw down the challenge of how to act so that this pattern of injury does not repeat itself. That is, they turn on the recognition of or identification with others across the barriers, among others, of suffering, marginalisation and abuse. The power of the idea of the universality of human rights draws strongly on the recognition across cultures that people are profoundly mistreated and that this should not happen. This response to the fact of abuse - persistent if hardly literally universal - is itself an assertion of the value of people, or more simply a recognition of the pain of the victim. And it remains a powerful response despite the fact that the recognition of the intolerable is perhaps rarely, if ever, a total and immediate grasp of the harm that is done and 
the harm that we do, but a dynamic understanding that learns and revises with some forms of harm seeming irreducible and others, often those within one's own social matrix, rendered almost invisible.

In this sense working with human rights in practice and in theory is one fertile way of grappling with some fundamental questions - how do we go about valuing each other, not solely as particular social agencies or roles but as people who, like oneself, are vulnerable beings (Fromm, 1960; Turner, 1993)? How do we build and sustain relationships and communities of mutual respect? What is it to live well together and how do we constitute the dynamics of power by which social agency is produced so that we do live well together? The idea of human rights thus addresses questions about power and participation, respect and the ways we construct the boundaries of exclusion and inclusion by which our identities and our communities take shape. The facts that the terms of such questions are not themselves clear and give rise to further questions, and that in the practical circumstances of our lives and at any but the most general level the answers may be not fixed, but shifting and partial, do not undermine their potency.

But if human rights can be understood as a kind of question and a way of working with those questions just posed they can also, and frequently are, understood as a quite definite set of answers - a set of answers that took shape as an element integral to the emergence of the modern liberal state. These two approaches to rights, as question and as answer, need not be mutually exclusive: awareness of both is important, but which of the two is given primacy makes a significant difference. For in this case the answers given, while substantial, do not exhaust the question.

\section{Human rights promotion and the 'foreign analogy'}

The approach to human rights taken here is to a large extent shaped by a focus on some of the problems of working with questions of suffering across national borders. By contrast, discussions of human rights set directly in a 'domestic' context or analyses that assume rights to be the jurisdiction of the liberal democratic state tend to place considerable emphasis on the definition and structure of rights - not surprisingly, since within a specific legal jurisdiction some of the fundamental questions raised by the subject can be taken as already settled, and sometimes quite reasonably so. Frequently, however, as the later discussion of the health of Indigenous Australians indicates, such analyses assume or demand a crucial zone of uniformity, whether within the state or more broadly - a realm of public discourse that is declared to be neutral and open to all citizens and others, but one that is repeatedly exclusionary. Moreover, it is easy to overlook or forget these practices of exclusion, simply because within states they have proved relatively effective, so that, for example, marginalisation can appear 
to be the consequence of the 'natural' characteristics of those marginalised. In international life, however, confronting questions of human rights can underscore the reality of difference (in forms of understanding and practice) - and difference that, in the form of a state, can wield power. Particularly if the intention is to have an effect on a certain practice in a certain place rather than simply to denounce it, response to abuse often involves concrete engagement with other forms of social practice in other political and legal jurisdictions. Thus, in an inversion of the domestic analogy, working with human rights in international life brings to the foreground the need to take difference seriously something that is arguably essential to the ways we understand human rights more generally.

There are, of course, well-established ways of handling difference in international life. The formal conception of the state system according to the principles of Westphalian order - particularly that of non-interference in the sovereign affairs of another state - is itself one set of ways of conceptualising and containing diversity. The traditional realist image of states as billiard balls, albeit of many colours, points vividly to what remains a dominant approach to difference in international life - that is, homogeneity more or less within states and difference among them, while all are subject to the same immutable dynamics of the struggle for survival and power (Tully, 1995: 10). In regard to human rights, then, difference may be seen as reason enough to reject the possibility of responding to forms of injury across borders. Here the discontinuity of the domestic political and legal jurisdiction between states is understood as paramount, and efforts to respond to abuse as threatening principles of non-interference, or (paradoxically) as threatening the vast welter of cross-border dealings which constitute the rhythms of contemporary life. Or, conversely and most powerfully, dealing with difference in the context of international human rights issues can be reduced to a confrontation between the evil empire and the forces of light.

As is discussed further in chapter 3, the assertion of difference between states but homogeneity within them establishes the billiard ball principles of identity around which the universalist versus relativist debate endlessly turns. It thus defines the standard cultural relativist defence by dominant political groups of their power to define the social, political and cultural realities within their state. But as later discussions in this text make clear, states (and cultures) are not homogenous. Thus engaging with human rights issues across borders draws attention to the need to work with diversity not only between but within states. Moreover, while borders are a blunt statement of difference and jurisdictional discontinuity, the corollary of this is that they are constantly crossed in myriad ways. They are a working part of networks of interaction, they are intersected by various patterns of relationship and solidarity (ethnic, cultural, religious, familial, commercial and so on), and as a statement of 
boundary and sovereignty are less a condition of autarchy than of membership of complex systems of state interaction.

Or difference can be downplayed or ignored by efforts at rights promotion internationally. It can be assumed that human rights are universally intrinsic to the person and that therefore difference is secondary or even a camouflage here, however, the person who is the locus of rights is often constituted from across a reasonably specific and narrow set of characteristics, as discussed in chapter 2. Or, more commonly, it can be assumed that whether or not human rights are intrinsically universal, they are part of the process of modernisation and of the evolution and expansion of the market that will gradually eradicate all but, again, a secondary difference. Or notions of human rights can be argued to be essentially specific to the liberal democratic state as epitomised by Western Europe and the English-speaking nations, but that this form of government is evidently the best, thus casting the problem as one of whether or how to ensure its reduplication in all countries.

When difference is downplayed the promotion of human rights in the international domain is approached like the delivery of a message - a message concerning known and established truths that may nevertheless require the use of significant pressure on the part of those delivering it. The message is, almost without exception, assumed to be one from 'us' to 'them', from West to East and North to South, from Athens to Persia. But, as was suggested earlier, questions of human rights do not simply ask us whether we should or how we can extend the rights observance in 'this world' here to 'that world' there. Rather, trying to respond effectively to abuse in another, as well as our own, place raises questions about what we mean by 'community' and 'identity', and how we work with and across difference. Approaching response to abuse as essentially the delivery of a message is mistaken in a number of ways. It is to assume, at least for a moment, not only that our liberal democratic traditions have valuable, if also profoundly mixed, historical experience and bodies of practice on the question of how to live together without generating significant systemic infliction of injury, but that these traditions have resolved such matters in an almost final form. It is to overlook the reality that 'this world' also generates abuse at home and abroad. It is to assume that the dominant models of rights and their categories of 'human' and 'community' represent the only or the superior forms within which these questions can be approached and that theories of liberal democracy are the only viable basis for a human rights practice. Most importantly, it is to assume that we have little or nothing to learn from others. And the message model of human rights promotion is mistaken not only in these substantive ways, but in its applicability: it is only in quite particular and limited circumstances that telling people across borders of state and other forms of difference what to do, even with some force, is an effective way of changing social practice. 
This, then, is the force deriving from an understanding of human rights as open-ended. If notions of rights operate as a way of identifying and working with patterns of injury, of asking questions and sometimes constructing answers about how to build political community that does not turn on such injury as a basis of political organisation or the assertion of power, but, to put it positively, turns rather on relationships of mutual respect, then it is important to recollect that no one culture, society or tradition of thought has a monopoly on how to cast and pursue these purposes. Working with and debate about human rights are parts of a conversation between and within cultures and communities, including those very particular collectivities that are states. A response to injury and to the questions it raises is an act of communication. To continue the metaphor of conversation, effective communication on human rights can not be simply the delivery of a message, although messages may at times be part of the exchange; it is an activity requiring and creating mutual understanding, and which leaves no participant entirely unchanged. Such communication is not a fixed or permanent achievement but an on-going engagement. Thus, no matter how resourceful the heterogeneous body of perceptions, institutional forms and practices that make up specifically Western liberal traditions of human rights can be as models of participative civility, they do not represent a final, sufficient or exhaustive truth but are part of a dynamic exchange. The 'answer' to particular occurrences of abuse, over what are sometimes the immensely slow processes in which social change takes place, emerges - or not - through the mutuality of communication.

This approach may appear at best romantic in the face of the pressing and grave violence of much abuse. A forceful response may be appropriate, on the rare occasions a forceful response is to hand, but it is likely to be only a temporary measure or part of a broader response. Outpourings of violence do not come from nowhere: systemic patterns of abuse are embedded in often complex knots of social practice - in people's collective construction of themselves and their network of relationships, identities, tasks and values. Abuse is not limited to the sheer physical act (the killing, the moment of torture or attack or exclusion from an essential activity) but is frequently made possible by the life practices and social institutions that in large part shape people's participation and identities within the communities that they at once inhabit and construct. Abuse is thus part of a positive (if violent or humiliating) construction of community. To shift such patterns may in many cases require persistent effort across a number of lines of attack over a considerable period of time; that is, it may require a substantive long-term engagement in the tasks of social change - the kind of engagement that we might take for granted in other commercial, political or social interactions.

The recognition of difference and the need for engagement with and communication across it that is highlighted by efforts to promote rights practices in 
international life can be applied to discussion of human rights in a domestic context. Working across borders can show us something of diversity, but diversity is not limited to or even epitomised by international borders. Nor are borders the assertion of unbreachable differences between internally homogenous cultures or states, as cultural relativist arguments suggest, or a sign of difference as necessarily exotic. Rather, the 'foreign analogy' is a reminder that boundaries and differences, and efforts to make some sense across them, are mundane realities within societies, cultures and states as well as between them. This approach builds on the tradition, deeply entrenched in liberal perspectives, of understanding rights as devices for enabling and defining participation. However, as James Tully (1995: 183) argues in regard to contemporary constitutionalism, a more open and dynamic sense of participation is needed - one that is able to listen to diverse voices and open to the practical exchange of 'limited and complementary stories'.

Indeed, lines of difference are perhaps the most common and probably the fundamental site of abuse. It seems likely that grave abuse in particular is nearly always inflicted across a deep division - of race, gender, class, belief - divisions that are significant enough to 'dehumanise' or to place those who bear the injury into a realm of non-person and outside the circle of possible empathy. Or, if they do not fit into a ready-made category of otherness, they can be construed as deficient in or as the enemy of whatever is taken to be the crucial identifying moment of humanity. Moreover, since people often display a propensity to cross the barrier, the act of abuse is itself an effort to entrench division between victim and other - as Elaine Scarry (1985) and David Grossman (1995) have argued. It is an endeavour to assert an ultimate difference of power, and a demand that any propensity to identify with the pain or predicament of another be overridden in this arrogantly declared and frightening gulf. Far from being limited to the extreme moments of torture, however, the process of division may be entirely routine and scarcely visible, as, for example, Jane Elliott's race discrimination exercises make plain. ${ }^{3}$

As Fromm (1977), Scarry (1985) and Grossman (1995) have in quite different ways explored in their discussions of torture and war, the relationship between the infliction of extreme pain on another and the exclusion of that person from the referential world of interchange, of self and other, is powerful. The ultimate exclusion of the person not just from life but from language, exchange and personhood by 'breaking him or her down' is not merely an additional consequence but one of the crucial objects of torture. It is an extreme but pervasive form of the organisation of political community and the assertion of power through the infliction of suffering. This dynamic of asserting one's own collective reality and potency on the destruction, pain, exploitation and exclusion of others may be at the heart of abuse of human rights. If abuse is a fundamental and constitutive act of exclusion, the effective recognition of 
human rights may turn upon people's mutual acceptance of each other as part of the world of exchange and communication - to move, in Patricia William's words, from 'human body to social being' (quoted in Brown, 1995: 96).

The notion of human rights can be understood as a demand or a reminder of the need to find some way across the division around which the particular injury in question is being generated, sufficiently at least to arrest or restrain the abuse. This is not to suggest, however, that if a way across a particular gulf becomes plain one arrives at a permanent territory of the human, or that there is any territory of the human. The category of the human is deeply paradoxical, appearing with the power of both innocent description and moral norm. Once the category settles and acquires stable content it frequently operates as an exclusionary mechanism patrolling the divisions between self and alien, addressed above, while at the same time appearing to maintain reference to an unimpeded universality. This enables a more powerful, or insidious, form of exclusion. As Richard Rorty comments in one of the numerous discussions of this very common phenomenon, the Serbs carrying out 'ethnic cleansing' 'take themselves to be acting in the interest of true humanity by purifying the world of pseudo-humanity'. Meanwhile '[w]e in the safe rich democracies feel about the Serbian torturers and rapists as they feel about their Muslim victims: They are more like animals than like us' (1993: $112,113)$.

Human rights talk is deeply imbued with this paradoxical sense of the 'human'. On the one hand, it calls to include all people simply by virtue of their humanness. On the other hand, rights talk becomes easily trapped into the moment of judgement - in identifying and condemning the perpetrator and the clean confronting the unclean. The confrontation of abuse can have, perhaps always has, great value in the dynamics of change: the naming of the destruction, the attribution of responsibility, even if in parts mixed, may be an essential step in moving past a climate of violence. Such, at least, is indicated by the response of relatives of many of those killed during the apartheid regime to the proceedings of South Africa's Truth and Reconciliation Commission. In a process still far from being played out, that Commission has endeavoured to step back from the dynamics of condemnation. While it has its own moment, condemnation leaves untouched the problem of recreating social relationships and identities in ways that do not simply recycle the abuse. Moreover condemnation can obscure the difficult reality that the perpetrators are as 'human' - as much like us - as the victims, and that today's victims can be tomorrow's perpetrators, and vice versa. Indeed, the act of condemning can itself be an effort to expel the perpetrators from the realm of the human and the possibility of exchange - a potentially dangerous though much-repeated move, if distinguishing 'ourselves from borderline cases' is indeed a fundamental element characterising abuse. 
Within international politics, and according to the Westphalian order, a distinction, indeed a complex opposition, is commonly drawn between the proper domain of politics and that of ethics, with human rights standardly classed with ethics. Questions of human rights are overtly ethical, in that they are concerned with the perennial questions with which abuse confronts us - with responding to the patterns of harm that we inflict on one another and with how to live, in the concrete circumstances of our collective and individual lives, in ways that do not require such patterns of harm. This is to draw on Indonesian poet and journalist Goenawan Mohamad's suggestion that a sense of rights starts with the face of the victim (1995). It does not start, that is and according to this understanding, with a theory of a fixed transcendental reality or of the state but from some movement towards and identification with the victim. Thus questions of rights are not necessarily ethical in the narrow and epistemologically driven sense of ethics that demands anchorage in a definitive ground of substantive, propositional truths or the actualisation of an idealist agenda. Questions of rights do not stand in opposition to, or take priority over, the mundane dynamics of politics, power and practicability but are part of the same knot of problems - 'the conduct of living and the living, is itself already ethical' (Gordon, 1991: 8).

This argument does not aspire to be visionary. Visions, whether of better futures or of permanent truths, can offer valuable energy; they can capture or inspire movements - most importantly, they can suggest to people that there are other ways of looking at things. However, if one of our senses is to be given precedence as a metaphor for understanding here it is listening, or a more general attentiveness to the forest of voices, rather than sight and its traditional association with an abstract grasp of crisp and timeless truths. As a culture we tend to focus on sight as a metaphor for knowledge and understanding: we see through to underlying truth or reality, envisage the future, seek new theoretical visions, and so on. Moreover, as a literate culture we associate sight with knowledge through the written word. Walter Ong's reflections (1982) are instructive here. 'Writing fosters abstractions that disengage knowledge from the arena where human beings struggle with one another. It separates the knower from the known' (44). 'Whereas sight situates the observer outside what he views, at a distance, sound pours into the hearer ... [Vision] comes to a human being from one direction at a time ... A typical visual ideal is clarity and distinctness ... The auditory ideal, by contrast, is ... a putting together' (72). 'For oral cultures, the cosmos is an ongoing event' (73). Sound is essentially evanescent and is sensed as such; vision 'favours immobility' (33). Metaphors of listening may assist more interactive, more open and less bordered ways of enacting knowing. Rights are traditionally associated with the activity of claiming, but they could be equally associated with listening. If notions of human rights and rights more generally are a way of recognising and taking part in the 
on-going interchange and negotiation among self and other, of requiring that one be properly heard, then they demand not only the ability and 'space' to claim participation, but also the ability and willingness to accord others attention.

However valuable models of human rights may be, we can carry to them only the understanding we develop, through application, in the more or less mundane obscurity of our own backyards. Following Robert Cox's notable critique, criticism is often made of the 'problem-solving approach' adopted in much international relations or political theory. ${ }^{4}$ Indeed, as Cox made clear, 'problem solving' can merely be a code-word for recycling problems, moving them from one beat to the next, without addressing their deeper causes. But if a concrete problem is actually resolved, the world changes a little and the field of possibilities, at once practical and theoretical, shifts. It may be worth treating with a little caution efforts to place a higher value on theory and its emancipatory potentials (with its promise of the capture of a truth behind mere activity) over people's efforts to shift the conditions that are to hand. Such work carries its own emancipatory possibilities. While the approach taken here is certainly not to attempt to 'solve' the case studies it considers, it nevertheless takes as its model the possibility of incremental work across many fields that can shift abuse by reconstituting fundamental social relationships.

The following two chapters explore some of the theoretical questions that have been touched upon in this introduction. Chapter 2 considers the Lockean account of human rights, as a leading model in international rights promotional activities, focusing on its construction of the categories 'human' and 'community'. Discussion then moves, rather briefly, to some of the dominant institutionalised ways of dealing with human rights made possible or illuminated by certain major theoretical approaches to international politics. Chapter 3 addresses more directly the universalist versus relativist debate which so characterises contemporary international discussion of human rights issues. In doing so, the chapter touches on the writings of some of the more critical analysts of ethics in international life, although essentially within the context of the debate on the nature of the grounds of rights.

Part II is a consideration of three case studies: the Tiananmen Square massacre of 1989; East Timor; and Australian Aboriginal health. The case studies were not chosen as examplary of the arguments put forward here - indeed in many respects they challenge those arguments. All, in their own way, are highprofile issues internationally or on a national stage, referred to repeatedly by the media in terms ranging from bell-like clarity (Tiananmen) to moral ambiguity and political confusion (Indigenous Australians). All occupy public as well as specialist imaginations. The case studies do not draw on original research or new empirical insights - this is not the nature of the argument. As well as drawing on the theoretical discussions of chapters 2 and 3, however, the case studies bring forth their own pattern of reflections. In particular, questions of 
citizenship rights mark all case studies, but are explicitly engaged in the examination of Indigenous Australian health. The conclusion endeavours to draw together more clearly the main themes to emerge from the earlier discussions and to indicate some of the contributions of this approach to a working human rights practice.

Something that this argument sets out to do, but perhaps does not always succeed in doing, is to be critical of certain streams of liberalism and modernity, without slipping into the position of rejecting them out of hand - in their totality as it were, as if they had a totality. 'Liberalism' is a broad term covering a complex range of traditions and debates while 'modernity' is at least as slippery. But, even more importantly, liberalism refers to a raft of social, political and economic practices, experiments and modes of government that grew out of particular historical circumstances, in response to particular problems and which are not necessarily reducible to theories of liberalism. The modern liberal state is 'an historically constituted form of community, one that has been subject to considerable variation across time and space' (Walker, 1993: 77). At the same time the effects of certain models and motifs - 'human', 'community' - are pervasive and powerful, and can be traced. This is the significance of using the language of tools and mechanisms. What is sought here, if not always found, is a sufficient distance to allow an appreciation of the tools we have to hand, and that avoids either a condemnation or an embrace of those tools, thereby enabling us to be more attentive to how well or how badly they may be working in the circumstances faced.

\section{NOTES}

1 'The primary ground for ethical reflection no doubt remains a capacity to identify the intolerable' (Walker, 1993: 52).

2 References to the Westphalian state system in this text are in line with usage in the study of international politics, where the phrase refers broadly to certain aspects of the modern state system, rather than with the tighter definitions more common to the study of history.

3 Jane Elliott has been running race discrimination exercises, mainly in the US, since the 1960s. The exercises turn on the attribution of identity - of capacity and incapacity on the basis of a single physical characteristic.

4 Robert Cox draws a distinction between critical theory and 'problem-solving' theory, which 'takes the world as it finds it' and sets out to make already given relationships and institutions 'work smoothly by dealing effectively with particular sources of trouble'. By contrast, critical theory 'is directed towards an appraisal of the very framework of action ... which problem-solving theory accepts as its parameters' (1981: 128f.). 